\title{
The economics of tobacco: myths and realities
}

\author{
Kenneth E Warner
}

\section{Introduction}

Each side in the debate about tobacco control - the tobacco industry and the public health community - wields a seemingly powerful set of economic arguments, the industry claiming that economic considerations urge a "go slow" approach to tobacco control, the public health community insisting they recommend an aggressive stance. Each of the most prominent arguments presented by both sides has a kernel of truth to it; yet each, in its own way, represents only a half truth. The industry uses its economic appeal with full knowledge of and intent to exploit its ability to deceive and mislead policy makers and the public. In contrast, tobacco control advocates frequently employ their economic rationale without full appreciation of its limitations. To inform both tobacco control advocates and policy makers more fully, this paper identifies the principal economic myths concerning tobacco and discusses their realities. The myths are associated with their purveyors by initials: TI for Tobacco Industry myths, and TC for myths perpetuated by the Tobacco Control community.

\section{Myth 1 (TI)}

Regardless of its health consequences, tobacco is crucial to a nation's (or region's) economy. Without the cultivation of tobacco, manufacture of tobacco products, and distribution and sale of products, a country's economy will suffer devastating economic consequences. Fobs will be lost, incomes will fall, tax revenues will plummet, and trade surpluses will veer dangerously in the direction of deficits.

REALITY

This is the tobacco industry's favourite economic myth. Conveyed to legislators and cabinet ministers (and journalists), its intent is to encourage the development of an indigenous tobacco industry within a given country, or to discourage the adoption of tobacco control policies likely to decrease tobacco product consumption.

The half truth in this myth resides in the fact that tobacco farming and product manufacture, distribution, and sale do constitute significant economic activities in many economies, and in the world as a whole. Globally, according to tobacco industry estimates, 33 million people farm tobacco, albeit many of them part time and most in addition to other crops. ${ }^{1}$ Approximately half that number work in tobacco product manufacture, distribution, and retailing. In addition, another 10 million or so are employed in supplier industries providing materials and services to the tobacco industry (for example, harvesting tools and cigarette papers, insurance coverage, and transportation and shipping). Excise (and other) tobacco taxation generates many tens of billions of dollars annually. ${ }^{2}$

Individual countries' tobacco economies vary greatly. Nearly half of the world's tobacco farmers (an estimated 15 million) live in China, the world's largest producer and consumer of tobacco; 3.5 million reside in India. Other countries exhibit substantial tobacco sectors as well, including Zimbabwe, Indonesia, Turkey, Bangladesh, Egypt, the Philippines, and Thailand. These countries are the exceptions to the rule, however. Tobacco farming constitutes a modest source of employment in most countries and tobacco manufacturing employment constitutes well under $1 \%$ of total manufacturing employment in most countries. ${ }^{1}$ Several countries derive $10 \%$ or more of total government revenues from tobacco taxation. However, in most countries, tobacco taxes generate only a few percent of total revenues. ${ }^{3}$

The public's perception of the industry's contribution to economic activity often exceeds the reality. For example, the economies of the six state "tobacco bloc" in the southeastern United States are perceived by many Americans to be heavily economically reliant on tobacco growing and manufacturing. In fact, only $1.6 \%$ of jobs in these six states are associated with the core tobacco sectors of the economy. ${ }^{4}$ Almost half of the tobacco counties in the US derive less than $1 \%$ of their income from tobacco farming, and the vast majority of tobacco farmers work off their farms, most holding full time jobs elsewhere. Indeed, there is only a single farm dependent county in the entire US that derives a majority of its farm revenues from tobacco. ${ }^{5}{ }^{6}$ According to a US Department of Agriculture economist, "tobacco plays a minor economic role in most local economies where it is grown". ${ }^{6}$

Although the importance of tobacco's role is often exaggerated in the public's mind, there is no denying that the number of people whose livelihoods depend on tobacco, at least in part, is substantial, both globally and in selected countries, as noted above. Many of the estimates emanating from tobacco industry public relations documents tend to inflate these numbers considerably, however, by including "expenditure induced employment" in addition to core tobacco sector jobs and those of industry suppliers. "Expenditure induced employment" refers to jobs created in all sectors of the economy when tobacco workers spend their incomes on other goods and services. Because this income "recycles" as it is spent over and over again, the expenditure 
induced employment effect tends to dominate estimates of total employment associated with tobacco sales. Yet similar employment would be created by workers from any industry spending a similar amount of income.

The myth in the tobacco industry's economic importance argument is that a significant economic presence necessarily implies significant economic dependence. Implicit in the industry's argument (occasionally explicit) is the notion that a decline in tobacco economic activity will entail a comparable decline in the economy of the country in question. In point of fact, when resources are no longer devoted (at all or as much) to a given economic activity, they do not simply disappear into thin air-the implication of the industry's argument. Rather, they are redirected to other economic functions. If a person ceases to smoke, for example, the money that individual would have spent on cigarettes does not evaporate. Rather, the person spends it on something else. The new spending will generate employment in other industries, just as the spending on cigarettes generated employment in the tobacco industry. Studies by non-industry economists in several countries have confirmed that reallocation of spending by consumers quitting smoking would not reduce employment or otherwise significantly damage the countries' economies..$^{7-13}$

The industry understands this reality. Pressed by a journalist, a US Tobacco Institute vice-president concurred that declining spending on tobacco would not necessarily mean that overall economic activity would be adversely affected. ${ }^{14}$ The industry's own economic consultants clearly perceive this truth, acknowledging it in their reports to the industry. ${ }^{15}{ }^{16}$ However, no industry public relations document has ever mentioned that alternative economic activity would replace declining tobacco activity.

The industry's retort to dismissal of its principal economic argument is to appeal to concerns about the high transition costs that declining consumption might create, focusing on tobacco industry workers thrown out of jobs. A particularly poignant image is that of poor tobacco farmers, their livelihood constantly in jeopardy because of the public health assault on tobacco. Certainly, any rapid decline in tobacco consumption could create transitional problems, for example brief periods of unemployment for cigarette plant manufacturing workers before they found new jobs, some in the industries that expand because of the reallocation of consumers' spending. However, the types of declines in tobacco consumption witnessed in the major industrialised nations are so gradual that they create few transitional problems of any consequence. As economist Thomas Schelling has observed, the principal effect of such diminution in tobacco use is not that tobacco farmers will be thrown out of work, but rather that the children of tobacco farmers will be less likely to go into tobacco farming than were their parents. ${ }^{17}$ This stands in stark contrast to the transitional problems that have accompanied many far more rapid shifts in industrial activity, such as the decline in the steel and shoe industries in the US.

Certainly, there are a few countries that are so dependent on tobacco that any substantial declines in their tobacco industries would represent genuine and important shocks to their economies, most notably Malawi (in which tobacco accounts for $60 \%$ of total export earnings) and Zimbabwe (23\%). ${ }^{1}$ Note that the problem for these countries lies not in the area of domestic tobacco control policy-declining domestic tobacco spending would not affect the trade balance-but rather in the global demand for exported tobaccos. Thus, campaigns to reduce domestic tobacco consumption could benefit the health of the citizenry of these countries without significantly damaging their economies. ${ }^{18}$

For selected countries, such as China, Brazil, and India, each with a large indigenous tobacco industry and each including a large proportion of smokers, making the transition from a tobacco dependent to a tobacco independent economy poses some special transitional challenges. The issues differ, too, between those countries in which tobacco products are manufactured and distributed by government monopolies and those in which the industry is privatised. Recognising, however, that even the most successful tobacco control campaigns tend to reduce consumption gradually, the real issue for all such countries is to reconcile the need to combat smoking for public health purposes with the need to ensure a smooth transition toward alternative economic enterprises.

Globally, concerns about the transitional costs associated with declining tobacco consumption evaporate when one recognises that tobacco consumption is rising, not falling. The World Health Organization predicts that the number of tobacco consumers will increase from 1.1 billion at present to 1.6 billion by the year 2025. ${ }^{1}$ Thus, for the foreseeable future, any realistic conception of successful international tobacco control must focus on reducing the rate of increase in tobacco use, rather than producing substantial absolute decreases in smoking. Globally, therefore, the "transitional costs" of successful tobacco control will involve less rapid expansion of the tobacco industry, rather than dire economic straits attributable to its contraction.

Elements of the industry's economic argument deserve the serious attention of country policy makers, especially the issue of tax revenues. Declining cigarette smoking frequently will mean declining revenues, as cigarettes are among the relatively few commodities singled out for product specific excise taxes. Any country now heavily reliant on tobacco excise taxation and embarking on a national tobacco control campaign will need to revisit the nation's tax policy. Note, however, that taxes represent transfers of money from citizens to their governments. They do not represent economic activity, in the sense of actual consumption of valuable resources. As such, 
the issue confronting countries will be how to fulfill revenue needs by redistributing the tax burden in an equitable manner, once tobacco tax revenues decline. The crux of the issue will not be a question of inflicting damage on the country's economy.

There is one important exception to this concern, examined in greater detail in consideration of industry myth 4 below; at least during the short and medium term, reducing tobacco consumption by raising tobacco excise taxes will increase government revenues at the same time that it diminishes the disease burden associated with tobacco use. ${ }^{19}$

The bottom line on myth 1 is that the tobacco industry's principal economic argument is not valid. With but the rare exception, aggressive tobacco control campaigns can proceed full speed ahead without fear of damaging a country's economy. Particularly if a country is a net importer of tobacco or cigarettes, the potential exists that modest short term economic gains will accompany the transition to a populace less hooked on tobacco. Reduced spending on imports will permit more domestic spending, with more employment thereby generated within the country.

Ironically, the tobacco industry itself is frequently responsible for more lost jobs in a given country's domestic tobacco industry than the most successful of national tobacco control campaigns. Industry induced job losses derive from at least three sources: (1) mechanisation of cigarette production plants, in which technology supplants factory workers ${ }^{20} ;$ (2) purchase of imported tobaccos, replacing domestically grown tobaccos raised by local farmers; and (3) wholesale price hikes that reduce cigarette sales, thereby diminishing industry employment while raising profits for the cigarette companies.

Myth 2 (TI)

Specific tobacco control policies will cause severe economic hardship in specific non-tobacco industries.

REALITY

A variant on myth 1 , the second industry myth is more targeted to both policy type and affected sector of the economy. Rather than arguing that policy induced reduction in tobacco consumption will hurt an entire economy, the industry claims that a specific policy, such as a ban on smoking in restaurants, will hurt a specific non-tobacco industry or sector of the economy, such as the restaurant industry of the community covered by the ban, or tourism within that community. Whereas myth 1 focuses on tobacco industry employment, myth 2 self consciously focuses on the economic implications of policy on non-tobacco industries. This myth relies on the belief that non-tobacco businesses hurt by tobacco control policies will be seen by legislators as bystanders in the war on smoking which become its undeserving casualties.

Myth 2 arose in the venue of workplaces and public accommodations in the US. The tobacco industry, and citizen groups and industries working with it, battled laws prohib- iting smoking in public places with the argument that such laws would penalise affected businesses, depriving them of smoking customers who would desert them, or increase their costs of doing business. With regard to the latter, opponents claimed that workplace smoking restrictions would make it more difficult to recruit and retain workers and cause smoking workers to take more frequent and longer breaks to replenish their nicotine depleted bodies.

The workplace is invariably an important battlefield for the tobacco industry, but perhaps inevitably it represents a losing fight for the industry. In the US, evidence on the health effects of environmental tobacco smoke $(\mathrm{ETS})^{21-23}$ raised the prospect of potentially ruinous lawsuits brought by non-smoking employees who claimed to have been sickened on the job by ETS. Further, in many settings, especially white collar workplaces, nonsmokers constituted the majority of employees and they preferred a smoke free environment. The highly educated (and low smoking) leadership of companies often favoured restrictions as a matter of principle. And evidence accumulated that banning (or severely restricting) smoking in the workplace actually paid economic dividends: contrary to the industry generated predictions, it often eased problems associated with worker recruitment and retention, and it reduced a myriad of other costs as well, including cleaning and maintenance of equipment and facilities. ${ }^{24}$

In recent years, the effects of laws banning smoking in restaurants (and most recently bars in California) have been the most publicised and controversial. In part this reflects the highly politicised battles over the passage of such laws ${ }^{25}$; in part it resulted from publication of empirical studies that demonstrated the absence of the dire consequences predicted by organisations representing the affected businesses. ${ }^{27-29}$

The argument against the laws has been that prohibiting smoking in restaurants in a given jurisdiction (for example, a city) would cause customers to flee to neighbouring jurisdictions that had laws more hospitable to smokers, thereby damaging the local restaurant industry. Similarly, cities (or states) "burdened" with "draconian" laws banning smoking in restaurants would lose both domestic and foreign tourists to more accommodating locales, producing declining payrolls and profits, failing businesses, and unemployment.

The empirical evidence has not supported the claim. In one study after another, covering multiple states within the US, analysts have found no adverse effect of smoking restrictions, including complete bans, on local restaurants' business. Indeed, several of the studies have found a tendency for smoking restrictions to increase business. Similar findings derive from analysis of the effects of smoking restrictions in bars (presumed the smoker's sacred territory) and of the impacts of restaurant and bar restrictions on tourism. ${ }^{29} 30$

Restaurant and bar associations and smokers' rights organisations have generated 
numerous rebuttals to the research findings, focusing on alleged methodological or data flaws or the contrary results of their surveys of the opinions of owners of the affected business establishments. ${ }^{30}$ Unlike the public health literature, however, these challenges have never themselves involved empirical analysis of objective experience.

Another example of myth 2 concerns restrictions on cigarette advertising. The tobacco industry argues that specific ad restrictions will have dire consequences for employment within a number of non-tobacco economic sectors. When a ban on cigarette advertising was proposed in Hong Kong, for example, the Association of Accredited Advertising Agencies issued an analysis by Coopers \& Lybrand that estimated that from 1450-1600 workers in non-tobacco industries would lose their jobs. ${ }^{31}$ Interestingly, only 50-100 of the job losses would occur among "primary service providers"-media providers and advertising agencies. The balance would be split between "support industries" (a third) and, especially, "community beneficiaries" (1000 jobs). In a US tobacco industry contracted study of the effects of advertising restrictions proposed by the Food and Drug Administration, the authors estimated substantial job losses, with printing and publishing firms "suffer(ing) the most." The authors acknowledged, however, that if these specific industries suffer job losses, other industries will realise compensating job gains. ${ }^{32}$

\section{Myth 3 (TC)}

Tobacco imposes an enormous financial burden on a country, greatly increasing health care costs to treat smoking produced diseases and reducing productivity.

REALITY

This is the tobacco control community's favourite economic argument. Not only does tobacco wreak havoc with physical health, the argument runs, it damages a society's fiscal health as well. Thus, far from representing an economic asset on society's balance sheet, as the industry suggests, tobacco constitutes a sizable liability.

Like the industry's principal economic argument, the validity of this argument rests on its interpretation and application. We begin with consideration of the health care expenditure implications of smoking and later turn to the issue of lost productivity.

Most societies devote a significant proportion of their health care resources to treating people made ill by smoking and other use of tobacco products (at least $6-8 \%$ in the $\mathrm{US}^{33}$ for example). It is certainly reasonable that a country should want to reduce smoking produced disease so that it could devote these resources to other health and social welfare needs.

It is also true, however, that non-smokers live longer than smokers, and thus that the health care costs of non-smokers during the "extra" years of their lives (compared to smokers) balance, at least to some extent, the higher costs smokers experience during each of their (fewer) years of life. Critics of the tobacco control community's economic argument cite studies that indicate that the net costs of smoking - the costs of treating smoking related illness minus the additional expenditures on non-smokers because they live longer-are small or non-existent. ${ }^{34}$

Whether smoking adds to or subtracts from aggregate medical expenditures remains a matter of dispute. A series of studies has produced contradictory results, reflecting differences in the studies' underlying assumptions, methods, and data. The most recent published analysis ${ }^{35}$ essentially supported the original conclusion of Leu and Schaub ${ }^{36}$ that the net cost is effectively zero, but critiques of the new study have found important flaws in it. ${ }^{37}$ In another prominent analysis, Hodgson concluded that smoking did add significantly to the net health care costs of the US. He even found that net smoking related expenditures might be positive during the years of senior citizenship (65 and older). ${ }^{38}$ Hodgson's seemingly contrarian finding resulted in part because he considered all of smokers' medical costs associated with consumption of cigarettes, not merely those associated with the principal smoking related diseases (cardiovascular disease, lung cancer, and chronic obstructive pulmonary disease). Studies that have found no significant impact on net costs have limited consideration to these major smoking related diseases. ${ }^{33}$

No such study ever compares the expenditures to the number of people benefiting from them. The entire reason that old age expenditures unrelated to smoking might balance out earlier (and concurrent) smoking related expenditures is that smoking ensures that there are fewer people around to utilise health care services! If, instead of comparing aggregate expenditures, one asked how per capita expenditures compare with and without smoking, one would likely find that per capita expenditures are considerably greater with smoking than without it. The net cost perspective also ignores how much people contribute to the health care system, through taxes and insurance premiums. Because a disproportionate number of smokers die young, their contributions to health care funding sources are smaller than those of longer lived non-smokers.

These caveats notwithstanding, it remains true that once the full story is appreciated, to appeal to the high medical costs of smoking as a fundamental reason to reduce smoking seems at least a bit disingenuous. Smoking may well impose a financial burden on health care budgets, but its net impact is likely modest.

Further research on that burden is still clearly warranted. Such research should include the medical costs associated with disease produced by ETS. Although the few estimates of such costs published to date have generally been relatively small, ${ }^{39}$ no published study has as yet considered the costs of ETS produced heart disease, which growing evidence suggests may be by far the single most important source of ETS related mortality. ${ }^{23} 40$

Country specific research must also consider how much of the financial expenditure for 
smoking related medical care represents a burden on the society and how much on individuals privately. Most of the literature on the medical costs of smoking does not distinguish between publicly borne and private costs. Many economists are quick to point out, however, that only the former technically constitute true social costs. ${ }^{34}{ }^{39}$ Although the public health perspective on social costs does not concur with this view, ${ }^{41}$ it warrants serious consideration. Clearly, governments' budgetary interest in the medical costs of smoking will depend on the extent of their involvement in financing their citizens' health care. In many countries, particularly the poorer nations of the world, government responsibility for treatment of chronic disease is modest at best.

In numerous studies of the social costs of smoking, productivity losses attributable to smoking exceed medical expenditures. Productivity losses result from smoking induced work absenteeism by employees sickened by smoking, and from foregone productivity among workers who die prematurely because of smoking produced disease. ${ }^{42}$

The problem of appealing to these costs as representing a social loss is that, as most economists view the matter, the costs are incurred privately, by the smokers and their families, as is the case for privately financed smoking related medical care. In other words, the fruits of the smokers' labour represent private benefits to their families; conversely the loss of smokers' labour imposes costs on the smokers' families, not on the society at large. (This perspective is incomplete, since it fails to consider that taxes on smokers' earned income represent benefits of their productivity derived by the larger society.) Of course, there are exceptions. If the premature demise of a smoker forces a previously self sufficient family onto the dole, the burden of the loss of support will be borne by the greater society through tax funded health and welfare programs; but this represents only a small fraction of the total smoking attributable productivity loss.

There are additional reasons that the productivity measurements typically overestimate the loss, even if one construes these private costs to represent social losses. For one, the labour market adjusts to reflect the excess smoking related work loss. This is never figured into the calculations of productivity loss that are found in the literature.

If one's objective is to tally the financial consequences of smoking, one must also consider smoking's implications for pension systems. In the US, research has demonstrated that smokers subsidise non-smokers' retirements. Because smokers die earlier on average than non-smokers, they receive less in social security benefits, despite having made roughly comparable contributions to the system during their lifetimes. ${ }^{43}$ In Great Britain, in contrast, smokers' greater disability leads to net pension payments to them. ${ }^{44}$ Thus, the implications of smoking for disability and pension obligations of government will vary from country to country. In a full examination of the fiscal consequences of smoking, they must be evalu- ated alongside the health care and productivity cost issues. However, care must be taken to distinguish smoking consequences that represent real resource consumption, such as smoking related medical care, from those such as social security transfers that produce only distributional consequences.

Smoking may well impose a net economic burden on a nation, but the magnitude of that fiscal concern pales in comparison with the enormity of the burden smoking exacts from the public's health. The tobacco control community must consider whether emphasis on the economic argument demeans the true importance of the battle against smoking.

\section{Myth 4 (TI)}

A large tax increase is undesirable because it will reduce government revenues by decreasing legal cigarette sales. This will result from decreased smoking and increased smuggling of lower priced cigarettes from neighbouring countries.

REALITY

Although this outcome is not impossible, it is extremely unlikely. Nearly all politically conceivable tax increases will generate increased revenues in virtually all countries.

The myth relies on two phenomena. First is the matter of how revenue reductions resulting from reduced purchase of cigarettes will compare with revenue increases from the higher unit tax rate. If the proportionate decline in tobacco consumption exceeds the proportionate increase in the tax rate, total revenues will fall. If the opposite holds, total revenues will rise.

In industrialised nations, the consensus estimate is that a $10 \%$ increase in cigarette price will produce approximately a $4 \%$ decline in the quantity of cigarettes demanded by smokers. More limited data from developing countries suggest that the impact may be in the order of twice as large. ${ }^{1}$

Note, however, that tax constitutes only a fraction of total price. Thus, if tax constitutes half of the price of a pack of cigarettes, for example, a doubling of the tax rate would increase retail price by only $50 \%$. As such, consumers would have to be extraordinarily price sensitive for consumption declines to exceed the rate of increase in tax, far more so than found in any study to date. For all politically feasible tax increases, revenue increases would be expected in nearly every country in the world, at least for some period of years. Empirical experience supports this expectation. ${ }^{19}$

The second element of myth 4 relates to the phenomenon of cross border smuggling. Clearly, inter-jurisdictional discrepancies in the prices charged for a product, if sufficiently large, create an incentive for people to buy the product in the low price jurisdiction and transport it for sale in the high price jurisdiction. Particularly where borders are not closely guarded, substantial differences in cigarette prices, often attributable primarily to differences in tax rates, create conditions conducive to cigarette smuggling. 
Whenever governments contemplate tobacco tax increases, the tobacco industry and its allies vigorously raise the spectre of a fiscal and criminal disaster. In 1994 this argument persuaded the Canadian government to cut its taxes substantially in response to the perception of dramatic losses in cigarette excise tax revenues attributable to smuggling from the US. ${ }^{45}$ In 1998 Sweden likewise slashed taxes in response to the same concern, following a $44 \%$ increase in Sweden's already high taxes from December 1996 to August 1997. ${ }^{46}$ The states in the US invariably confront an armada of tobacco industry lobbyists making the same argument each time an excise tax increase is under consideration.

Evidence shows that the fears raised by the industry often greatly exaggerate the magnitude of the problem. In the Canadian case, federal and provincial government tax revenues fell $\mathrm{C} \$ 1.2$ billion the year after the tax cut, contrary to expectations raised by the industry's campaign, and smoking among children increased. ${ }^{45}$ Before its reduction, the Swedish tax increase had increased tax revenues by $9 \%$ and decreased smoking among both sexes and both young and older smokers. ${ }^{46}$

Smuggling remains a legitimate concern, in part because the tobacco industry itself appears to tolerate and actively encourage it, as indicated by recent court cases in which tobacco company executives have been found guilty of complicity in smuggling operations. ${ }^{46} 47$ The industry certainly benefits from increased sales associated with smuggling. Worldwide, nearly a third of legally identified exports find their way into the contraband market. As Joossens and Raw have shown, ${ }^{46} 48$ however, the determinants of smuggling are far more complicated than one might expect. They include countries' general tolerance of corruption and specific failure to police smuggling. In Europe, smuggling problems appear to be more serious in the low price countries; at least the authors find no positive correlation between price and the size of a country's smuggling problem. This does not negate the importance of inter-jurisdictional price differences, but it does emphasise that many factors are at work, with price differences not necessarily the dominant influence.

Smuggling can be successfully combatted through better and more complete record keeping, the use of prominent tax stamps, increased penalties for violation of the law, vigorous enforcement of the law, the banning of in-transit trade, and other supply restrictions. ${ }^{46}{ }^{48}$ More conscientious self policing by the cigarette manufacturers could substantially reduce smuggling.

The essential observation is that the threat of smuggling is systematically exaggerated by the tobacco industry to combat increased taxes that will discourage purchase of its products. The author is aware of no documented instances of tax revenues declining when tax rates were increased.
Myth 5 (TI)

Even if a tax increase would raise government revenues and decrease smoking, it is fundamentally unfair because its burden would fall disproportionately on the poor. Taxes should be proportional or progressive (that is, taking the same (proportional) or a larger proportion (progressive) of the income of the affluent); they should not be regressive (taking a larger share of the income of the poor than of the wealthy).

REALITY

In most nations, more of the poor smoke than do the rich. As a consequence, the poor often spend a substantially larger proportion of their incomes on cigarettes than do the affluent. This means, in turn, that the poor bear a disproportionate share of the burden of a cigarette tax. Increasing the tax, it stands to reason, will increase this disproportionate burden even more. (This will not always be true. Particularly in poor countries, affluent smokers are likely to smoke many more cigarettes per day than do poor smokers. If the number of cigarettes smoked rises more rapidly than does income, the tax burden will fall proportionately more heavily on the affluent smokers. This possibility will be enhanced if, as is often the case, affluent smokers consume premium, possibly foreign brands of cigarettes, while poor people smoke much less expensive domestic brands. If taxes are tied to price, rather than number of cigarettes, the burden will fall more heavily on smokers of the high priced brands.)

As this regressivity argument appears to be compelling, it is often the source of great concern to tobacco control advocates and legislators who genuinely want to do something to decrease the burden of smoking. Fortunately, the argument is not necessarily true. Even if it is true, the feared regressivity of a tax increase will be far smaller than that forecast by budget analysts, with tools available to legislators to minimise and even eliminate the feared inequity.

A given tobacco tax typically will be distributed regressively. A tax increase, however, may not be regressive. This can result because the poor are typically considerably more responsive to price changes than are the affluent. In the United Kingdom, for example, Townsend and colleagues found that the demand for cigarettes within social class I (the most affluent) was almost entirely unresponsive to price increases, while it was quite responsive within social class $\mathrm{V}$ (the poorest). ${ }^{49}$ Thus, as the tax rate rises in the UK, few affluent smokers are deterred from smoking and hence their tax burden rises roughly proportionately with the tax rate. Among smokers in social class $\mathrm{V}$, in contrast, a tax rate increase is met with a decline in the number of cigarettes smoked of nearly the same proportion. For the class as a whole, the tax burden rises modestly, if at all. The burden of the tax increase is thus experienced disproportionately by the social class most able to afford it.

In the US, Farrelly and colleagues found that lower income persons had a price responsiveness $70 \%$ greater than those with higher 
incomes. ${ }^{50}$ Chaloupka found a similar relationship between education, which is correlated with income, and price response-the least educated were the most price responsive. ${ }^{51}$

Lacking more evidence, we cannot conclude with certainty that this relationship holds in general. Further, if in a given country the differences in price responsiveness across the income spectrum are smaller than those found in the UK, the burden of a tax increase might be distributed regressively; but again, the burden of the increase will be less regressive than is the burden of the existing tax.

Legislators can reduce concerns about inequity by dedicating some portion of the revenues from the increased tax to assist low income smokers to quit. A sizable majority of low income smokers in developed countries report that they would like to quit. Given their financial circumstances, however, they may have limited access to professional help and pharmaceutical quitting aids. The mix of greater price responsiveness among the poor and allocation of revenues toward smoking cessation in this group can make the net impact of the tax increase measure progressive.

In short, the potential regressivity of a tobacco tax increase represents much less of a concern than one might expect. That its use by the tobacco industry to fight such increases is disingenuous is demonstrated by the fact that the industry never expresses the same concern when raising its own wholesale prices. The economic burden on the poor who smoke is identical.

Two additional issues warrant mention in considering the effects of tax increases. One is that the theory underlying optimal taxation calls for a proportional or progressive tax system. However, every individual component of an overall tax system need not be proportional or progressive. Thus, even if a cigarette tax increase were regressive, it might well be justified on other grounds, with other components of a country's tax system determining the overall degree of progressivity. ${ }^{40}$

One such ground constitutes the second issue warranting attention here: precisely because poorer smokers are more price responsive than more affluent smokers, a tax increase will cause more poorer smokers to quit smoking. Especially given that in industrialised nations poorer smokers suffer disproportionately from the diseases caused by smoking, a larger proportion of the eventual health benefits of quitting will accrue to the low income population. In this regard, increasing the cigarette tax is clearly a "progressive" public health policy.

The issue of equity raises concerns in the world's poorest countries even if the burden of a cigarette tax is distributed progressively (that is, the rich pay proportionately more of it, compared to income, than do the poor). In these countries, although poor smokers consume fewer and less expensive cigarettes than more affluent smokers, the paucity of their incomes makes any additional tax, regressive or otherwise, a genuine burden. Of course, given their poverty, more such individuals would be induced to avoid (or minimise) smoking in the face of a sizable tax increase.

\section{Myth 6 (TC)}

At the same time that health ministries urge their citizens not to smoke, governments in many countries subsidise tobacco growing. This is hypocritical, and damaging to the health of the nation. By encouraging tobacco growing, the subsidy encourages smoking.

REALITY

This myth is likely predominantly true, although the reason differs dramatically from the direct link that tobacco control activists perceive, at least in a country in which the "subsidy" system is similar to that in the US. Many American activists believe that government support of tobacco growing increases the supply of tobacco products. In point of fact, the direct impact of the US system is exactly the opposite.

Given that different countries' approaches require different interpretations, the issue must be addressed in the context of a specific approach to "subsidising" tobacco growing. To illustrate the analytical thinking one must devote to this matter, this discussion focuses exclusively on the system known best to the author, the US tobacco agriculture support system.

The US system is a complicated mix of price supports and output restrictions. ${ }^{19}{ }^{52}$ Its two principal components are a system of allotments used to permit the growing of tobacco and to limit annual output to predetermined quantities and price supports that set minimum prices farmers receive for their crops. The allotments are licenses to grow tobacco, similar to liquor licenses required to sell alcoholic beverages to the public. Developed in the 1930 s during the Great Depression, the allotments were originally distributed to then existing tobacco farmers. Without an allotment, owned or rented, a farmer cannot legally grow tobacco. This in itself restricts production. Production is further restricted by the US Department of Agriculture setting the maximum output per type of tobacco each year, the quantity depending on anticipated purchases by the major cigarette producers and stocks remaining from the previous year.

The price support system establishes a minimum price per pound. If the price at auction falls below this minimum, a cooperative buys unsold tobacco and holds it for sale in a subsequent year.

Rather than encourage cigarette sales and consumption, the direct effect of this system is to discourage smoking, by increasing the price of cigarettes. Supply restrictions increase the price of tobacco, as do minimum support prices. Were tobacco grown and sold in a free market, supplies would be larger and prices lower. As such, to the extent that cigarette manufacturers use domestically produced tobacco, the cost of the major raw ingredient in their cigarettes will be higher than it would be 
otherwise. All other things being equal, this increases the price of the finished product.

As it turns out, the impact is very small. Tobacco itself constitutes only $3 \%$ of the retail price of cigarettes, and the allotment/price support system is estimated to increase the price of domestically grown tobacco by about $18-23 \% .^{53}$ Since the manufacturers of cigarettes in the US buy approximately a quarter to a third of their tobacco abroad, the net impact of the tobacco "subsidy" system is to raise the price of cigarettes by no more than 1 cent per pack. ${ }^{52}$ Given an overall price elasticity of demand for cigarettes in the neighbourhood of $-0.4,{ }^{19}$ the direct effect of the tobacco agriculture support system is to reduce the number of cigarettes smoked in the US by an estimated $0.23 \%{ }^{52}$

This outcome runs contrary to the conventional wisdom that the US tobacco support system increases smoking. When one factors in political considerations, however, it is entirely plausible, even likely, that that is the net impact of the existence of the system. One of the principal consequences of the tobacco support system in the US has been to create a strong political constituency supporting tobacco. The political power of the tobacco bloc in the US Congress is legendary, with legislators from the tobacco growing region in the southeastern US fiercely devoted to protecting the economic interests of tobacco farmers, the allotment owners (the true beneficiaries of the tobacco agriculture regulatory system ${ }^{54}$ ), and, to a lesser extent, those of the cigarette manufacturers. An almost certain consequence of this concentrated political power has been congressional inaction on tobacco control policies. In the absence of the tobacco bloc, it is quite possible that Congress would have adopted much higher cigarette taxes, nationwide restrictions on smoking in public places, and stronger restrictions on tobacco advertising and promotion. Thus, the tobacco protective political constituency created by the system almost certainly has had the net effect of encouraging smoking, simply by severely limiting tobacco control policy making. ${ }^{52}{ }^{55}$ As such, in the context of the US system the tobacco control community's conclusion about the impact of the "subsidy" system is likely correct, although the logic leading to that conclusion has been fallacious.

It is imperative to reiterate that different countries' systems differ sufficiently from one another and that the analysis of their impacts will vary, potentially substantially. Some countries truly do subsidise the growth of tobacco or tobacco product manufacturing, a policy that, other things being equal, does encourage smoking by increasing supply and decreasing price.

\section{Myth 7 (TC)}

The tobacco companies have moved into developing countries in recent years in an effort to compensate for the decline in markets in the world's most affluent nations. Ongoing tobacco control victories in rich countries will be paid for by increasingly aggressive invasion of poor countries by the multinational companies.

\section{REALITY}

There is no doubt that the multinational tobacco companies have moved aggressively into the world's poorer nations in recent years, often attempting to develop an indigenous tobacco industry (tobacco farming and/or finished product manufacturing), always trying to expand tobacco product consumption. In countries with a longstanding tradition of smoking, the industry employs sophisticated marketing techniques to compete with domestic brands of cigarettes, increase daily consumption among existing smokers, and encourage traditionally low smoking groups to "modernise" by becoming smokers (for example, young women in many Asian societies). ${ }^{56} 57$ According to the one empirical study that has examined its impact, the introduction of modern western advertising in Asia increased cigarette consumption by about $10 \% .^{58}$

Many tobacco control advocates believe that the multinationals' move into developing countries is a direct result of declining markets at home. Cigarette consumption is falling gradually in the most industrialised nations (about $1.5 \%$ per year); it is increasing in low and middle income countries (about $2.1 \%$ per year)..$^{56}$ The logic seems almost inescapable: as the profit balloon is squeezed in the developed nations, the industry's activity necessarily bulges out into the less exploited and hence more promising developing country markets. The corollary is that success in controlling tobacco use in the First World exacerbates the tobacco epidemic in Second and Third World nations. Thus, policy and other tobacco control victories in western countries are blemished by their inevitable negative repercussions for the rest of the world. A cause otherwise to be celebrated is converted, at least in part, into a reason to feel guilt. This was a primary concern in the international community during the debate in the US on the proposed comprehensive settlement of lawsuits against the tobacco industry. ${ }^{57}$

Although the argument sounds compelling, there is no evidence to support it. Tobacco profits are not a zero sum game. Rather, they are whatever the tobacco industry can make them, subject to the laws of supply and demand and interventions of governments, helpful or otherwise. No rational profit maximising firm would await diminished profit at home before venturing abroad into lands promising new opportunities for profit. To the contrary, all profit oriented firms will seek out profits wherever and whenever they are available.

Although there is a correlation between declining tobacco consumption in the west and industry expansion into the east, no evidence points to causation. A better explanation of the multinationals' contemporaneous move into other countries is the development of a fortuitous set of economic circumstances: the general easing of trade barriers for all international commerce ${ }^{59}$ (a function of technological and economic improvements in product distri- 
bution and marketing, as well as the easing of legal impediments); the emergence of a level of consumer income in such countries adequate to support consumption of western cigarettes; and the bulging treasuries of multinational tobacco companies that permit expansion overseas.

Lost in the conventional wisdom is the fact that declining consumption in western nations is not always accompanied by declining profits. In the US, over the past quarter century during which per capita consumption has fallen by more than a third, ${ }^{60}$ Philip Morris and RJ Reynolds have frequently reported new record annual profits. Every time the companies increase their wholesale prices, they decrease their sales but increase their immediate profits, a reflection of the fact that the demand for cigarettes in the US is inelastic. Thus, Philip Morris and RJ Reynolds can raise their prices and increase profits at the same time that they bemoan decreases in cigarettes smoked. (One might wonder why, if this is true, the companies do not increase their prices all the way to the point that profits are maximised. The answer likely lies in the distinction between short run and long run profit maximisation for an addictive substance. Prices that maximise profits in the short run may drive enough new and potential customers out of the market so as to decrease future (long run) profits. Interestingly, as tobacco control efforts succeed in reducing the prospects for the marketing of cigarettes in the future, the cigarette companies may choose to raise prices more in the pursuit of short run profit maximisation. ${ }^{61}$ )

To put the general issue into perspective, the United States - one of the principal villains in this piece-includes about $4 \%$ of the world's 1.1 billion tobacco consumers. A small decline in US consumption, even were it to reduce profits, would have a barely discernible impact on the number of tobacco consumers worldwide (for example, a $10 \%$ decline in the number of US smokers would reduce the world's tobacco consuming population by about $0.4 \%$ ). Even if tobacco consumption were expanding in the US, the modest potential effect on global industry profits would still mean that companies seeking future profit centres would necessarily look overseas. In a profit driven global marketplace, the multinational tobacco companies intensify their pursuit of foreign markets independent of their successes or failures in First World countries.

Tobacco control successes in developed nations thus are unadulterated successes. They do not have negative ramifications for tobacco use in other societies, and in fact are likely to have precisely the opposite effect, by serving as models for national tobacco control.

\section{Myth 8a (TI)}

Cigarette advertising and promotion have no effect on the amount of smoking. Their only function, and impact, is to distribute the number of cigarettes sold among the rival companies.

\section{Myth 8b (TC)}

Cigarette advertising and promotion constitute one of the principal determinants of smoking, especially initiation of smoking by children.

REALITY

The battle over cigarette marketing certainly stands as one of the major fronts in the tobacco wars. At issue are such diverse concerns as the propriety of the advertising of an addictive substance to which children are inevitably exposed and constitutional protections of commercial free speech. At stake are principles, the public's health, and substantial economic interests, in the advertising industry as well as within the tobacco industry.

The principal issue is whether or not advertising and other forms of promotion affect smoking decisions: whether to try smoking; how much to smoke; whether to quit; whether to remain abstinent once one has quit smoking. Some of the more subtle mechanisms by which advertising may increase smoking receive little public attention-for example, the impact of constant visual cues to smoke (such as billboards) on the number of cigarettes existing smokers consume, or the effect of the media's dependence on cigarette advertising revenues on coverage of the hazards of smoking, ${ }^{62}$ and the impact, in turn, of reduced coverage on the public's appraisal of the severity of the risk posed by smoking. ${ }^{63}$ Rather, attention focuses primarily (although not exclusively) on the earliest of smoking decisions: whether to begin.

The tobacco industry and the tobacco control community take diametrically opposite positions on this critical matter. The industry insists that advertising and promotion have no impact on children's decision to start smoking, nor on anyone else's for that matter. Many tobacco control advocates believe fervently that the seductive imagery of tobacco ads and promotions plays a significant role in initiating what are often life long nicotine addictions.

One need dig only slightly below the surface of the industry's claim to conclude that it is likely quite disingenuous. Particularly in countries in which only one or two companies control the vast majority of the market, advertising would appear to be a futile gesture if its sole function was to vie for slices of a pie of fixed size ${ }^{64}$ In the US, for example, in which Philip Morris controls half of the market (and RJ Reynolds half of the remainder), if Philip Morris succeeds in getting an existing smoker to switch brands, the smoker as likely as not switches from one of the company's own brands to another. The profit potential in such an enterprise is obviously quite limited. One must wonder, therefore, why a company like Philip Morris would not jump at the opportunity to have cigarette advertising banned, thereby saving billions of dollars annually without (according to the industry's argument) losing sales. Indeed, the major companies likely would be the principal beneficiaries of an ad ban, since established brands fare best when advertising is not permitted. Yet Philip Morris, RJ Reynolds, and the rest of the American industry have vigorously opposed multiple 
opportunities to ban cigarette advertising legislatively. ${ }^{64}$

The logic underlying the proposition that advertising and promotion play a significant role in kids' decisions to start smoking is substantial, ${ }^{65}$ enhanced by seemingly compelling research. ${ }^{66}$ The empirical evidence relating marketing to smoking decisions is less substantial and less compelling. The literature is replete with analyses that show that children attracted to cigarette ads or promotional materials are more likely to express interest in smoking or actually begin smoking subsequently. ${ }^{67-69}$ But no study has as yet dealt adequately with the possibility that interest in smoking attracts children to cigarette ads, rather than the reverse.

The econometric literature on the effects of advertising has focused on the relation between spending on advertising and promotion and overall (hence primarily adult) cigarette consumption, rather than smoking by children per se. One group of studies finds no evidence of an impact of advertising on cigarette consumption; a roughly equal number of studies finds a significant, although quite small, impact. Econometric approaches have distinct limitations in evaluating the fundamental question, however. ${ }^{19}$

Another approach to assessing the impact of advertising on consumption is to examine the outcomes of advertising and promotion bans. If bans reduce smoking, one can infer that advertising increases it. Scores of countries have adopted partial or complete bans, permitting analysis of the association between adoption of restrictions and subsequent changes in the prevalence of smoking. Several years ago, a prominent review of the international evidence concluded that bans did reduce smoking. ${ }^{70}$ Industry supported critiques of the analysis found fault with it, however. ${ }^{71}$ Recently, Saffer and Chaloupka ${ }^{72}$ have developed compelling theoretical and empirical evidence that complete bans can have a significant impact on smoking, while partial restrictions have little impact, primarily because the industry can find alternative means of promoting their product that are nearly as effective as those prohibited. According to these authors, compared to unrestricted advertising and promotion, a complete ban would decrease cigarette consumption by approximately $6 \%$.

In 1989, the US surgeon general concluded that the weight of the evidence strongly favoured the proposition that advertising does influence smoking. ${ }^{73}$ The surgeon general also concluded, however, that the extent of advertising's influence on smoking, and especially on the initiation of nicotine addiction by children, was unknown and possibly unknowable. A wealth of evidence indicts other factors, including peer, parental, and role model behaviour, as potentially more important. ${ }^{67}$ In its unprecedented decision to regulate the sale and distribution of cigarettes and smokeless tobacco products to protect children, published in 1996, the US Food and Drug Administration indicted advertising as a "substantial, contributing, and therefore material factor" in children deciding to smoke. The agency acknowledged, however, "that advertising may not be the most important factor."74

Advertising is an attractive target for tobacco control activists in part because of its visibility and, of course, its symbolism. It is also attractive because, unlike peer and parental behaviour, it is amenable to control through public policy. Expectations for the potential impact of greatly reducing advertising and promotion, or even eliminating them altogether, must be kept in perspective, however. The collective evidence suggests that an advertising and promotion ban would reduce smoking, likely including both the initiation of smoking by children and the maintenance of smoking by adults, albeit modestly. A ban would be no tobacco control panacea, however. Rather, it would represent but a single piece in the jigsaw puzzle of effective tobacco control, one we continue to struggle to put together.

\section{Conclusion}

Interest in, even obsession with, the economics of tobacco reflects the old adage that "money talks". Focusing on the economic implications of tobacco cultivation, product sales, tax revenues and the like permits the tobacco industry to deflect attention from the domain in which it inevitably faces a humiliating, and of course costly, defeat, namely public health. It shifts tobacco control from the arena of health policy to that of fiscal policy. That the industry finds a receptive ear for its economic arguments merely supports the wisdom of the old adage. This bait-and-switch strategy has forced the public health community to fight the industry on the industry's chosen battleground.

Both sides have honed seemingly compelling cases. Yet each side's arguments survive only because of their self evident grains of truth. Missing from the public debate, and from the knowledge base of those who make public policy, is the fallacy that underlies each argument, the reason that, as used, it is misleading. Ironically, from the perspective of the group of analysts who care most about monetary matters - economists - the economic issues in tobacco are interesting but not fundamentally important. The fundamentally important issue is the four million people killed by tobacco each year, and the 10 million who will follow annually three decades hence. ${ }^{1}$ If the tobacco control community can develop a sophisticated appreciation of the essence of tobacco economics, and convey that understanding to public decision makers, perhaps we can force the issue of tobacco back where it properly belongs, in the domain of public health.

This work was prepared with the assistance of grant \#026421 from the Robert Wood Johnson Foundation of Princeton, New Jersey. I am indebted to Frank Chaloupka, two anonymous referees, and journal senior editor Gary Giovino for helpful comments on a previous draft. 1 World Bank. Curbing the epidemic: governments and the
economics of tobacco control. Washington, DC: The World economics of 
2 Agro-Economic Services Ltd. and Tabacosmos Ltd. The employment, tax revenue and wealth that the tobacco industry creates. London: Agro-Economic Services, 1987.

3 Chapman S, Wong WL. Tobacco control in the third world: a resource atlas. Penang, Malaysia: International Organization of Consumers Unions, 1990.

4 Price Waterhouse. The economic impact of the tobacco industry on the United States economy. Arlington, Virginia: Price Waterhouse, 1992

5 Gale F. Tobacco dollars and jobs. Tobacco Situation \& Outlook. US Department of Agriculture, Economic Research Service, TBS-239; September 1997:37-43.

6 Gale F. Economic structure of tobacco-growing regions. Tobacco Situation E Outlook. US Department of Agriculture, Economic Research Service, TBS-241; April 1998:40-7.

7 Irvine IJ, Sims WA. Tobacco control legislation and resource allocation effects. Canadian Public Policy 1997;23:259-73.

8 Warner KE, Fulton GA. The economic implications of tobacco product sales in a nontobacco state. $\mathscr{f} A M A 1994$ 271:771-6.

9 Warner KE, Fulton GA, Nicolas P, et al. Employment implications of declining tobacco product sales for the regional economies of the United States. $7 A M A 1996$ 275:1241-6.

10 Buck DC, Godfrey C, Raw M, et al. Tobacco and jobs. York, UK: Society for the Study of Addiction and the Centre for Health Economics, University of York, 1995.

11 McNicoll IH, Boyle S. Regional economic impact of a reduction of resident expenditure on cigarettes: a case study of Glasgow. Applied Economics 1992;24:291-6.

12 van der Merwe R. Employment and output effects for Bangladesh following a decline in tobacco consumption. Wash ington, DC: Population, Health and Nutrition Department, The World Bank, 1998

13 van der Merwe R. An empirical analysis of the output effects of cigarette taxes in South Africa and the regional impact. In: Lu R, Mackay J, Niu S, Peto R, eds. The growing epidemic. Singapore: Springer-Verlag. In press.

14 City Newspaper, Rochester, New York, October 16, 1986, p $1,6-8$.

15 Chase Econometrics. The economic impact of the tobacco industry on the United States economy in 1983. Bala Cynwyd, Pennsylvania: Chase Econometrics, 1985.

16 American Economics Group. The US tobacco industry in 1994: its economic impact on the states. Washington, DC: American Economics Group, March 1996.

17 Schelling TC. Economics and cigarettes. Prev Med 1986; 15:549-60

18 Warner KE, Fulton GA. Importance of tobacco to a country's economy: an appraisal of the tobacco industry's economic argument. Tobacco Control 1995;4:180-3.

19 Chaloupka FJ, Warner KE. The economics of smoking. In: Newhouse J, Culyer A. Handbook of health economics. Amsterdam: Elsevier. In press.

20 Joossens L. Employment in the tobacco sector in the EEC. Europe for Smoking Prevention. Newsletter 6, p 6. Brussels,
Belgium: Belgian Association for Smoking Prevention, Belgium: Belgian Associati
August/September 1989.

21 US Department of Health and Human Services. The health consequences of involuntary smoking. A report of the Surgeon General, 1986. Rockville, Maryland: Public Health Service, Centers for Disease Control, Center for Health Promotion and Education, Office on Smoking and Health. Washington DC: US Government Printing

22 US Environmental Protection Agency. Respiratory health effects of passive smoking: lung cancer and other disorders. Report no. EPA/600/6-90/006F. Washington, DC: EPA, Office of Health and Environmental Assessment, Office of Research and Development, 1992.

23 Glantz SA, Parmley WW. Passive smoking and heart disease: mechanisms and risk. $7 A M A$ 1995; 273: 1046-53.

24 US Environmental Protection Agency. The costs and benefits of smoking restrictions. An assessment of the smoke-free environment act of 1993 (HR. 3434). Washington, DC:
EPA, Office of Air Radiation, Indoor Air Division, April EPA, Office of Air Radiation, Indoor Air Division, April 1994.

25 Public interest pretenders. Consumer Reports May 1994; 316-20

26 Traynor MP, Begay ME, Glantz SA. New tobacco industry strategy to

27 Glantz SA, Smith LRA. The effect of ordinances requiring smoke-free restaurants on restaurant sales. Am f Public Health $1994 ; 84: 1081-5$.

28 Glantz SA, Smith LRA. The effect of ordinances requiring smoke-free restaurants and bars on revenues: a follow-up. Am F Public Health 1997;87:1687-93.

29 Glantz SA, Charlesworth A. Tourism and hotel revenues before and after passage of smoke-free restaurant ordinances. FAMA 1999;281:1911-18.

30 Alberta Tobacco Control Centre. The economic impact of smoke-free restaurant bylaws. Alberta, Canada, June 22, 1999

31 Coopers \& Lybrand. A study of the economic impact of a ban on cigarette advertising in Hong Kong. Hong Kong, Coopers \& Lybrand, 1996

32 American Economics Group. Economic impact in the states of proposed $F D A$ regulations regarding the advertising, labeling and sale of tobacco products. Washington, DC: American Economics Group, March 1996.
33 Warner KE, Hodgson TA, Carroll CE. The medical costs of smoking in the United States: estimates, their validity, and their implications. Tobacco Control 1999;8:290-300.

34 Viscusi WK. Cigarette taxation and the social consequences of smoking. In: Poterba JM, ed. Tax policy and the economy. Cambridge, Massachusetts: Massachusetts Institute of Technology Press, 1995:51-101

35 Barendregt JJ, Bonneux L, van der Maas PJ. The health care costs of smoking. N Engl f Med 1997;337:1052-7.

36 Leu RE, Schaub T. Does smoking increase medical expenditures? Soc Sci Med 1983;17:1907-14.

37 Hodgson TA. The health care costs of smoking. N Engl f Med 1998;338:470.

38 Hodgson TA. Cigarette smoking and lifetime medical expenditures. Milbank $Q$ 1992;70:81-125.

39 Manning WG, Keeler EB, Newhouse JP, et al. The taxes of sin: do smokers and drinkers pay their way? $\mathcal{F} A M A 1989$;

40 Warner KE, Chaloupka FJ, Cook PJ, et al. Criteria for determining an optimal cigarette tax. Tobacco Control 1995; 4:380-6.

41 Cook PJ. The social costs of drinking. In: Norwegian Ministry of Health and Social Affairs. The negative social Health and Social Affairs, 1991:49-81.

42 Hodgson TA, Meiners MR. Cost-of-illness methodology: a guide to current practices and procedures. Milbank Memorial Fund Quarterly 1982;60:429-62.

43 Shoven JB, Sundberg JO, Bunker JP. The social security cost of smoking. In: Wise DA, ed. The economics of ging.
Chicago: University of Chicago Press, 1989:231-54.

44 Atkinson AB, Skegg JL. Anti-smoking publicity and the demand for tobacco in the UK. The Manchester School of Economic and Social Studies 1973;41:265-82.

45 Sweanor DT. The smuggling of tobacco products. Ottawa, Ontario: Smoking and Health Foundation, 1997.

46 Joossens L. Impact of smuggling and cross border shopping on world wide consumption. Washington, DC: Population, Health and Nutrition Department, The World Bank, January 1999.

47 Dow Jones Newswires. RfR affiliate to pay $\$ 15 M$ for acting as smuggling front. December 22, 1998.

48 Joossens L, Raw M. Cigarette smuggling in Europe: who really benefits? Tobacco Control 1998;7:66-71.

49 Townsend JL, Roderick P, Cooper J. Cigarette smoking by socioeconomic group, sex, and age: effects of price, income, and health publicity. BMF 1994;309:923-6.

50 Farrelly MC, Bray JW, Office on Smoking and Health. Response to increases in cigarette prices by race/ethnicity, income, and age groups-United States, 1976-1993. MMWR Morb Mortal Wkly Rep 1998;47:605-9.

51 Chaloupka FJ. Rational addictive behavior and cigarette smoking. Fournal of Political Economy 1991;99:722-42.

52 Zhang P, Husten C. Impact of the tobacco price support program on tobacco control in the United States. Tobacco Control 1998;7:176-82.

53 Zhang P, Husten C, Giovino G. The impact of the price support program on cigarette consumption in the United States. Atlanta, Georgia: Office on Smoking and Health, Centers for Disease Control and Prevention, 1997.

54 Babcock BA, Foster WE. Economic rents under supply controls with marketable quota. American fournal of Agricultural Economics 1992;74:630-7.

55 Warner KE. The tobacco subsidy: does it matter? f Natl Cancer Inst 1988;80:81-3.

56 Connolly GN. Worldwide expansion of transnational tobacco industry. Fournal of the National Cancer Institute Monographs No 12. International Conference on Cancer Prevention, 1992:29-35.

57 Hammond R. Addicted to profit: big tobacco's expanding global reach. Washington, DC: Essential Action, 1998.

58 Chaloupka FJ, Laixuthai A. US trade policy and cigarette smoking in Asia. NBER Working Paper No 5543. Cambridge, Massachusetts: National Bureau of Economic Research, 1996.

59 Chaloupka F, Corbett M. Trade policy and tobacco: towards an optimal policy mix. In: Abedian I, van der Merwe R, Wilkins N, Jha P, eds. The economics of tobacco control: towards an optimal policy mix. Cape Town, South Africa: Applied Fiscal Research Centre, University of Cape Town, 1998:129-45.

60 Tobacco Institute. The tax burden on tobacco. Historical compilation 1995. Vol 30. Washington: Tobacco Institute, 1998.

61 Becker GS, Grossman M, Murphy KM. An empirical analysis of cigarette addiction. American Economic Review 1994;84:396-418.

62 Warner KE, Goldenhar LM, McLaughlin CG. Cigarette advertising and magazine coverage of the hazards of smoking: a statistical analysis. $N$ Engl F Med 1992;326:305-9.

63 Marsh A, Matheson J. Smoking attitudes and behavior. An enquiry carried out on behalf of the Department of Health and Social Security, Office of Population Census and Surveys. London: HMSO, 1983.

64 Tye JB, Warner KE, Glantz SA. Tobacco advertising and consumption: evidence of a causal relationship. 7 Public Health Policy 1987;8:492-508.

65 Warner KE. Selling smoke: cigarette advertising and public health. Washington: American Public Health Association,

66 Fischer PM, Schwartz MP, Richards JW Jr, et al. Brand logo recognition by children aged 3 to 6 years: Mickey Mous and Old Joe the camel. $\mathscr{F} A M A$ 1991;266:3145-8. 
67 US Department of Health and Human Services. Preventing tobacco use among young people: a report of the Surgeon Genlic Health Service, Centers for Disease Control, National Center for Chronic Disease Prevention and Health Promotion, Office on Smoking and Health, Washington. (US Government Printing Office Publication No S/N 017-001-00491-0.)

68 Pierce JP, Choi WS, Gilpin EA, et al. Tobacco industry promotion of cigarettes and adolescent smoking. $\mathfrak{f} A M A$ 1998;279:511-5.

69 Siegel M, Hingson R, Biener L. The influence of tobacco marketing and counteradvertising on smoking initiation among youth. Presented at the annual meeting of the Robert Wood Johnson Foundation Substance Abuse Policy Research Program. Charleston, South Carolina, December 10, 1998.

70 Laugesen M, Meads C. Tobacco advertising restrictions, price, income, and tobacco consumption in OECD coun-

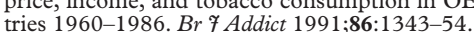

71 Stewart MJ. Tobacco consumption and advertising restrictions: a critique of Laugesen and Meads (1991). International fournal of Advertising 1992;11:97-118.

72 Saffer H, Chaloupka FJ. Tobacco advertising: economic theory and international evidence. Cambridge, Massachusetts: National Bureau of Economic Research, Working Paper No 6958, February 1999.

73 US Department of Health and Human Services. Reducing the health consequences of smoking: 25 years of progress. A report of the Surgeon General. Atlanta: US Department of Health and Human Services, Public Health Service, Centers for Disease Control, National Center for Chronic Disease Prevention and Health Promotion, Office of Smoking and Health, 1989. (DHHS Publication No (CDC) 89-8411.)

74 US Food and Drug Administration. Regulations restricting the sale and distribution of cigarettes and smokeless tobacco to children and adolescents: final rule. Federal Register August 28, 1996;61:44476.

\section{Reviewers for Tobacco Control}

In 1999, 140 people assisted in providing reviews for original articles. The editors would like to thank these people most sincerely for their efforts. Without them, peer review would not be possible.

\begin{tabular}{ll} 
Michael Alavanja & James Davis \\
Eva Alberman & Richard Daynard \\
Harmony Allison & Joe DiFranza \\
Robert Anderson & Annette Dobson \\
Jeffrey Arnett & Rob Donovan \\
David Ashley & Douglas Eadie \\
Edith Balbach & Arthur Farkas \\
Scott Ballin & Matthew Farrelly \\
Clive Bates & Ellen Feighery \\
Adrian Bauman & Jeffrey Fellows \\
Michael Begay & Roberta Ferrence \\
Neal Benowitz & Brian Flay \\
Lisa Bero & Brian Flynn \\
Anthony Biglan & Jean Forster \\
Richard Bonnie & Jonathan Foulds \\
Ron Borland & Don Garner \\
David Buck & Elizabeth Gilpin \\
David Buller & Afaf Girgis \\
John Cairns & Joe Gitchell \\
Frank Chaloupka & Stanton Glantz \\
Laurie Chassin & Tom Glynn \\
Won Choi & Christine Godfrey \\
Joanna Cohen & Margo Goodin \\
Suzanne Colby & Neil Grunberg \\
Greg Connolly & Prakash Gupta \\
Rob Cunningham & Jeffrey Harris \\
Candace Currie & Gerard Hastings \\
Daniel McGoldrick & Jack Henningfield \\
& \\
\hline
\end{tabular}

$\begin{array}{ll}\text { Deborah Hennrikus } & \text { Mimi Nichter } \\ \text { David Hill } & \text { Jennifer O'Loughlin } \\ \text { Bert Hirschhorn } & \text { Tracy Orleans } \\ \text { Andrew Hyland } & \text { Rosalie Pacula } \\ \text { Maritta Jaakkola } & \text { John Pauly } \\ \text { Peter Jacobson } & \text { Andrew Penman } \\ \text { Konrad Jamrozik } & \text { Cheryl Perry } \\ \text { Martin Jarvis } & \text { John Pierce } \\ \text { Leonard Jason } & \text { Stephen Platt } \\ \text { Luk Joossens } & \text { Rudolf Poledne } \\ \text { Murray Kaiserman } & \text { Richard Pollay } \\ \text { Lynn Kozlowski } & \text { Linda Pucci } \\ \text { Tim Lancaster } & \text { Thomas Radecki } \\ \text { Anne Landman } & \text { Dorothy Rice } \\ \text { Harry Lando } & \text { Bill Rickert } \\ \text { Nadine-Rae Leavell } & \text { Arja Rimpela } \\ \text { Scott Leischow } & \text { Chris Roberts } \\ \text { Scott Lennox } & \text { Lyn Roberts } \\ \text { David Levy } & \text { Leslie Robinson } \\ \text { Edward Lichtenstein } & \text { Robert Robinson } \\ \text { Jim Lightwood } & \text { Todd Rogers } \\ \text { Willard Manning } & \text { Laurie Ruggiero } \\ \text { Danny McGoldrick } & \text { Henry Saffer } \\ \text { William McIntosh } & \text { Jon Samet } \\ \text { David Mendez } & \text { James Sargent } \\ \text { Jane Moore } & \text { Penny Schofield } \\ \text { Joel Moskowitz } & \text { Caroline Schooler } \\ \text { Cheryl Moyer } & \text { Michelle Scollo } \\ \end{array}$

Seth Emont

Herb Severson

Don Sharp

Julia Shelley

Donald Shopland

Michael Siegel

John Slade

Fran Stillman

Theresa Stockwell Teti

Jeffrey Stoddard

Daniel Stokols

Victor Strecher

Stephen Sugarman

Charyn Sutton

David Sweanor

Michael Thun

Scott Tomar

Joy Townsend

Wayne Velicer

Jeanette Ward

Ken Warner

Cassandra Welch

Andrew Wilson

Susan Woodruff

Alistair Woodward

Trevor Woollery

Robert Wyckham

Shu-Hong Zhu 